\title{
mHealth In Comprehensive Geriatric Service- The Way Forward
}

\section{Suguna Anbazhagan ${ }^{1}$, Surekha Anbazhagan ${ }^{2}$, Sahithyaa Jaysingh ${ }^{3}$}

${ }^{1}$ Assistant Professor, Department of Community Medicine, Mahatma Gandhi Medical College and Research Institute, Shri Balaji Vidyapeeth University, Pillaiyarkuppam, Pondicherry-607402; ${ }^{2}$ Assistant Professor, Department of Community Medicine, Shri Sathya Sai Medical College and Research Institute, Shri Balaji Vidyapeeth University, Kancheepuram District, Chennai-603108; ${ }^{3}$ Assistant Professor, Department of Community Medicine, Mahatma Gandhi Medical College and Research Institute, Shri Balaji Vidyapeeth University, Pillaiyarkuppam, Pondicherry-607402

\section{Corresponding Author}

Dr Surekha Anbazhagan, Assistant Professor, Department of Community Medicine, Shri Sathya Sai Medical College and Research Institute, Shri Balaji Vidyapeeth University, Kancheepuram district, Chennai Tamil Nadu-603108

E Mail ID: surecommed87@gmail.com

\section{Citation}

Anbazhagan S, Surekha A, Saahithya J. mHealth In Comprehensive Geriatric Service - The Way Forward. Indian J Comm Health. 2020;32(2):341-343.

\section{Article Cycle}

Source of Funding: Nil Conflict of Interest: None declared

Received: 06/04/2020; Revision: 21/04/2020; Accepted: 19/05/2020; Published:30/06/2020

This work is licensed under a Creative Commons Attribution 4.0 International License.

\section{Abstract}

The projected increase in the number of disabled older persons poses a challenge for health care and social services. (1) Multiple health problems of such people will require an integrated approach.(2) While the elderly have unique assessment needs, these are often not addressed adequately. Usually only the presenting illness of the elderly are adequately addressed and the 'Non-medical' \& 'Non-presented' issues are not looked into. Many of these issues are not presented to the treating physician as patients \& families presume that these are part of normal aging. The importance of comprehensive geriatric assessment is that, it permits a systematic evaluation \& documentation of all the issues that concern this population and identification of problems could lead to implementation of corrective and or preventive measures. There is evidence to suggest that a variety of $M$ health techniques can be applied effectively and safely in geriatric medicine in providing comprehensive geriatric service across a variety of clinical settings.

\section{Keywords}

mHealth; Elderly; Comprehensive Geriatric Service; India

\section{Introduction}

The major determinants of population ageing are declines in fertility, mortality and increase in life expectancy.(3) The elderly population in India defined as those above 60 years of age forms $7.5 \%$ of the total population currently.(4) It is projected that this will go up to $11.9 \%$ by 2031 and $17.3 \%$ by 2051.(5) Within the next five years, it is expected that the number of adults aged 65 and over will outnumber children under the age of 5 , and by the year 2050, older adults will outnumber children under the age of 14.(6)

Most elderly have chronic diseases like Diabetes mellitus, Hypertension, Coronary heart disease \& arthritis. Additionally, they have age related disabilities such as impaired vision, impaired functional status, impaired hearing and cognitive dysfunction and it is important to identify and address these issues at the earliest, so as to improve their quality of life $\&$ prevent morbidity related to these issues. The term "Geriatric Syndromes" is used to address these issues.(7)"Geriatric syndrome" is a term that is often used to refer to common health conditions in older adults that do not fit into distinct organ-based disease categories and often have multifactorial causes. The list includes conditions such as cognitive impairment, delirium, incontinence, malnutrition, falls, gait disorders, pressure ulcers, sleep disorders, sensory deficits, fatigue, and dizziness. These conditions are common in older adults, and they may have a major impact on quality of life and disability. Geriatric syndromes can best be identified by a comprehensive geriatric assessment.

Comprehensive geriatric assessment: Comprehensive Geriatric Assessment (CGA) is defined as a multidisciplinary diagnostic and treatment process that identifies medical, psychosocial, and functional limitations of a frail older person in order to develop a coordinated plan to maximize overall health with aging. $(8,9)$ The information generated is used to develop treatment and 
long-term follow-up plans, arrange for primary care and rehabilitative services \& institute preventive measures where appropriate.

The CGA team: The range of health care professionals working in the assessment team varies based on the services provided by individual comprehensive geriatric assessment programs. In many settings, the CGA process relies on a core team consisting of a physician, nurse, and social worker and, when appropriate, draws upon an extended team of physical and occupational therapists, nutritionists, pharmacists, psychiatrists, psychologists, dentists, audiologists, podiatrists, and opticians. Although these professionals are usually on-staff in the hospital setting, very few are available in the community setting and access to and reimbursement for these services have limited the availability of CGA programs. Increasingly, CGA programs are moving towards a "virtual team" concept in which members are included as needed, assessments are conducted at different locations on different days, and team communication is completed via telephone or electronically, often through the electronic health record.(10)

m health in Comprehensive geriatric service: $M$ Health (Mobile health) is a general term for the use of mobile phones and other wireless technology in medical care. Patient satisfaction is generally reported as high. (11)The $M$ health system for delivery of CGA is needed in response to three primary challenges:

- The assessment information of patient is not easy to save and hard to further data analysis (e.g., data mining).

- $\quad$ Geriatric consultation is delivered by geriatricians and gerontic nurses, sometimes with support from other allied health specialists. This process is time consuming and involving much human resource.

- The dependence on rare and expensive geriatrician time is reduced without compromising quality of care or accuracy of decisions.

The geriatric service using mobile application like Epicollect functions as follows: Healthcare provider both at primary health care setting and also at community level assesses elderly patients who may require routine health care or permanent residential care or tertiary level management. After the initial assessment and comprehensive geriatric assessment, and entry in the mobile Epicollect application, the detailed report will be show on the system. The patient's data can be further analysed automatically, generating further reports immediately -Can be referred to tertiary care hospital if required and managed for further complications. In feasible settings consultation via telephone by geriatricians and management of specific issues by specialists at primary health care level can be done. These comprehensive reports can be a replacement for handwritten progress notes.
The Framework: The overall care rendered as a part of Comprehensive geriatric assessment can be divided into six steps:

- Data-gathering

- Discussion among the team, including the patient and/or caregiver as a member of the team

- Development, with the patient and/or caregiver, of a treatment plan

- Implementation of the treatment plan

- Monitoring response to the treatment plan

- Referral if needed

- Follow up

Formal assessment tools of CGA can reduce the burden on the clinician/geriatrician and can be performed by any health care provider at community level/primary care setting with adequate training. (12)

MAJOR COMPONENTS - Core components of comprehensive geriatric assessment (CGA) that should be evaluated during the assessment process using $M$ service are as follows:

Vision

Hearing

Locomotion

Depression

Fall risk

Cognition

Additional components may also include evaluation of the following:

Nutrition

Urinary continence

Sexual function

Dentition

Poly-pharmacy

Social support

Financial concerns

Advance care preferences

Activities of daily living: An older adult's functional status can be assessed at three levels: basic activities of daily living (BADLs), instrumental or intermediate activities of daily living (IADLs), and advanced activities of daily living (AADLs).

Evidence from past trials: Comprehensive Geriatric assessment and care coordination can be highly effective and also cost effective. CGA programs for patients discharged to home from the emergency department were found to be effective at reducing emergency department visits and hospital admission.(13)CGA coupled with an adherence intervention using $M$ service designed to empower the patient and prompt the primary care clinician to adhere to CGA recommendations was evaluated in a randomized trial.(14) Among communitydwelling older persons with functional disability, urinary incontinence, falls, or depressive symptoms, those randomly assigned to CGA with adherence intervention had less functional decline, less fatigue, and better social 
functioning over a 15-month period compared with the control group.

In a randomized trial evaluating CGA followed by six months of interdisciplinary primary care versus usual primary care in a population at risk for high health care utilization, those randomly assigned to treatment had reduced functional decline, depression, and use of home health services compared with the control group over 15 to 18 months following randomization.(15)

In A Trial of Annual in-Home Comprehensive Geriatric Assessments for Elderly People Living in the Community in California it was found that a three-year program of comprehensive in-home geriatric assessments coupled with $M$ health resulted in a significant reduction in the number of persons who required assistance in performing the basic activities of daily living and a significant reduction in the number of permanent nursing home admissions.(16)

Implementing the mobile based application like Epicollect to gather information and incorporating into the electronic medical records of primary care supports the use of a reliable and valid tool at the point of service. Using $M$ tools in delivering comprehensive geriatric service in the primary care setting or community setting guides healthcare providers to make more meaningful and comprehensive healthcare decisions, which in turn improve patients' clinical outcomes. This $\mathrm{M}$ health model of comprehensive geriatric service in primary care and at community level demonstrates healthcare cost savings over time by addressing frailty at an early stage, avoiding costly hospital admissions.

\section{Conclusion}

Research suggests that Comprehensive geriatric assessment using $M$ health can lead to optimized prescribing; reduce the incidence of adverse drug events, the need for specialty services, diagnostic studies, ER visits, and hospitalizations; and improve outcomes. Home geriatric assessment has been shown to be effective in improving functional status, preventing institutionalization, and reducing mortality.(9)

In areas where geriatrician expertise is currently unavailable, $M$ service has the capacity to allow for service, which can be supported by a trained health care provider locally, using a protocol for comprehensive geriatric assessment.

\section{Authors Contribution}

All authors have contributed equally.

\section{References}

1. Jackson ME, Siu AL, Drugovich ML, et al. Alternative projections of the disabled elderly population: report to the Administration on Aging. Washington, D.C.: Public Health Service, 1991.

2. Indira Jai Prakash, editor. Aging and well-being of old people, In: Indira Jai Prakash editor. Aging: emerging issues. 1st ed. India: Globe Folders; 2003; 15-18.

3. Roger Detels, James McEwen, Robert Beaglehole and Heizo Tanaka. Oxford text book of Public Health: The Practice of Public Health. Oxford University Press. 2002; 3(4): 1714.

4. Park's Text Book of Social and Preventive Medicine.21st edition. India: M/s BanarsidasBhanot Publishers 2011; 446

5. Population ageing and health in India - prediction based on Census 2001. (Online), Available from http://www.cehat.org/humanrights/rajan.pdf

6. Aging facts - WHO. (Online), (Dated 13 Aug 2012), Available from http://www.who.int/kobe_centre/mediacentre/forum/forum_wh d-2012/en

7. Fauci AS, Braunwald E. Geriatric Medicine, In: Lisa B. Caruso editor. Harrison's principles of internal medicine. 17thed. New York: McGraw Hill, Health Professions Division; 1998; 57-59.

8. Stuck AE, Siu AL, Wieland GD, Adams J, Rubenstein LZ. Comprehensive geriatric assessment: a meta-analysis of controlled trials. Lancet. 1993 Oct 23;342(8878):1032-6. doi: 10.1016/01406736(93)92884-v. PubMed PMID: 8105269.[PubMed].

9. Devons CA. Comprehensive geriatric assessment: making the most of the aging years. Curr Opin Clin Nutr Metab Care. 2002 Jan;5(1):19-24. doi: 10.1097/00075197-200201000-00004. Review. PubMed PMID: 11790944.[PubMed].

10. Katherine $T$ Ward, David B Reuben, Comprehensive geriatric assessment, Upto date: Available on URL: https://www.uptodate.com/contents/comprehensive-geriatricassessment

11. Brignell $M$, Wootton R, Gray L. The application of telemedicine to geriatric medicine. Age Ageing. 2007 Jul;36(4):369-74. doi: 10.1093/ageing/afm045. Epub 2007 Apr 20. Review. PubMed PMID: 17449535.[PubMed],

12. Elsawy B, Higgins KE. The geriatric assessment. Am Fam Physician. 2011 Jan 1;83(1):48-56. Review. PubMed PMID: 21888128. [PubMed].

13. Caplan GA, Williams AJ, Daly B, Abraham K. A randomized, controlled trial of comprehensive geriatric assessment and multidisciplinary intervention after discharge of elderly from the emergency department--the DEED II study. J Am Geriatr Soc. 2004 Sep;52(9):1417-23. doi: 10.1111/j.1532-5415.2004.52401.x. PubMed PMID: 15341540.[PubMed].

14. Reuben DB, Frank JC, Hirsch SH, McGuigan KA, Maly RC. A randomized clinical trial of outpatient comprehensive geriatric assessment coupled with an intervention to increase adherence to recommendations. J Am Geriatr Soc. 1999 Mar;47(3):269-76. doi: 10.1111/j.1532-5415.1999.tb02988.x. PubMed PMID: 10078887. [PubMed].

15. Boult C, Boult LB, Morishita L, Dowd B, Kane RL, Urdangarin CF. A randomized clinical trial of outpatient geriatric evaluation and management. J Am Geriatr Soc. 2001 Apr;49(4):351-9. doi: 10.1046/j.1532-5415.2001.49076.x. PubMed PMID: 11347776.[PubMed].

16. Stuck AE, Aronow HU, Steiner A, Alessi CA, Büla CJ, Gold MN, Yuhas KE, Nisenbaum R, Rubenstein LZ, Beck JC. A trial of annual in-home comprehensive geriatric assessments for elderly people living in the community. N Engl J Med. 1995 Nov 2;333(18):1184-9. doi: 10.1056/NEJM199511023331805. PubMed PMID: 7565974.[PubMed] 